\title{
Embracing the Fourth Industrial Revolution: The Effectiveness of Work Integrated Learning
}

\author{
Obianuju Ebele Okeke-Uzodike, ${ }^{1, *}$, Emem Anwana² \\ ${ }^{1}$ Department of Applied Management, Faculty of Management Sciences, Durban University of Technology, South Africa \\ ${ }^{2}$ Department of Applied Law, Faculty of Management Sciences, Durban University of Technology, South Africa
}

Received July 3, 2020; Revised August 17, 2020; Accepted September 11, 2020

\begin{abstract}
Cite This Paper in the following Citation Styles
(a): [1] Obianuju Ebele Okeke-Uzodike, Emem Anwana, "Embracing the Fourth Industrial Revolution: The Effectiveness of Work Integrated Learning," Universal Journal of Educational Research, Vol. 8, No. 12, pp. 6394-6404, 2020. DOI: 10.13189/ujer.2020.081205.
\end{abstract}

(b): Obianuju Ebele Okeke-Uzodike1, Emem Anwana (2020). Embracing the Fourth Industrial Revolution: The Effectiveness of Work Integrated Learning. Universal Journal of Educational Research, 8(12), 6394-6404. DOI: 10.13189/ujer.2020.081205.

Copyright $\odot 2020$ by authors, all rights reserved. Authors agree that this article remains permanently open access under the terms of the Creative Commons Attribution License 4.0 International License

\begin{abstract}
Work Integrated learning within the South African purview was introduced into the Higher Education system not only to align students to the world of work, but also to address the skills gap and shortages within society. The emergence of the Fourth Industrial Revolution, and its perceived challenges, require not only the government but various stakeholders to explore innovative and creative ideas and ways of thinking aimed at managing the technologically-driven business environment. In view of this, this article examines the extent to which work integrated learning prepares students in terms of readiness for the Fourth Industrial Revolution. The article adopted a qualitative research approach using structured interviews with students and focus group from a workshop engagement involving three identified stakeholders: a University of Technology, students, and the Department of Education. The findings of the study demonstrated the positive impact of Work Integrated Learning in students' work preparedness and further, provided in-depth knowledge on various challenges detrimental to students' skills and knowledge development for the world of work. The implications of this study impact the effective roles of key stakeholders in addressing the required competencies needed in readiness for the Fourth Industrial Revolution. The study recommends, amongst others, aligning the education system to the needs of the economy.
\end{abstract}

Keywords Work Integrated Learning, Higher Education, Fourth Industrial Revolution, Skills/Knowledge, Employability

\section{Introduction and Background}

Friday $5^{\text {th }}$ July 2019, marked a memorable day for South Africa (SA) in the wave of the Fourth Industrial Revolution (4IR) as the country launched its first 4th Industrial Revolution SA - Digital Economic Summit. While addressing the summit, President Cyril Ramaphosa highlighted the potential opportunities by 4IR in seven key areas, including the need to improve education outcomes and skills [73]. Improving the quality of the education system in South Africa has been an ongoing refrain in the public discourse and a top priority of the democratic government. The South African education system has been undergoing various challenges, which are well-documented in research, ranging from poor academic performance, poor quality of teachers, unprepared students, poor attitude towards education, and teachers, inequality, teacher/lecturer absenteeism, and the narrow pass rate focus $[42,29,64,47,40]$. The high dropout rate of school learners [29], contributes to the sky rocketing youth unemployment rate, which is presently at $55.2 \%$ [70], posing a great concern not only for the government but for society in general. These challenges, traced back to the apartheid education system, have manifested in manpower skills development challenges and shortages facing the nation. The emergence of the 4IR in the midst of these challenges creates more distress and questions the future of 
the younger generation. The South African government has long implemented reforms and strategies to improve the quality of the education system and its outcomes. Such efforts have seen in the South African education system the introduction of Outcomes-Based Education (OBE), the implementation of work integrated learning, and building partnerships between Higher Education Institutions (HEI) and industries.

The philosophy of OBE has been adopted by countries around the world in an attempt to align industry's need to educational output. The concept of OBE is driven by the need to move away from a content-based curriculum to a life-long learning approach, and its learning principle is built around specific educational goals or outcomes. Thus, researchers define OBE as a student-centred approach in curriculum design, in which teaching is aligned to what learners should know, understand and demonstrate, to cope with life beyond the educational environment $[38,13])$. The idea behind this is to enable learners to achieve outcomes that support them within and beyond the industry environment. In the South African context, critics of OBE have questioned its effectiveness in improving the quality of education given the on-going discourse on the employability of graduates. Scholars have argued the use of curriculum intervention strategies such as Work Integrated Learning (WIL) and building partnerships to complement OBE in achieving its objectives. The concept of WIL has been adopted across South African higher education institutions. It has seen HEI's engaging and building partnerships with industries in an effort to address the on-going education and labour market challenges.

Against this backdrop, this article addresses the question "To what extent is Work Integrated Learning preparing University of Technology students in the acquisition of skills and knowledge required to tackle the anticipated challenges envisioned with the emergence of the 4IR?" In an effort to address this question, the main research aim is to examine the effectiveness of Work Integrated Learning in the work preparedness of University of Technology (UoT) students to embrace the 4IR. Subsequent research objectives emerging from the main question are:

- To provide insight into the use of WIL in preparing students to acquire the necessary skills and knowledge in readiness for the 4IR.

- To understand the challenges facing stakeholders in the use of WIL to build an effective workforce.

- To determine the role of the stakeholders in ensuring effective development of skills and knowledge.

In finding answers to these research objectives, data were drawn from three stakeholders: a sample of students pursuing a National Diploma in a University of Technology in South Africa, a set of representatives from an unidentified UoT and representatives from a government department. As part of the curriculum requirement, the students undergo work integrated learning for a period of five months in different government departments/establishments. Data was drawn from a dialogue session involving a UoT, students undergoing a WIL program and a government department hosting the WIL students. Motivation for the study stemmed from the authors of this article and their responsibilities as part of the stakeholders in improving the quality of the education system and ensuring the achievement of an appropriate learning outcome towards long-life learning. In addition, giving the staggering youth unemployment rate, the authors felt the need to understand how well WIL prepares the students and what shortcomings, if any, may affect the readiness of the students to tackle the potential negative impact of 4IR. Some insight into this aspect would help the authors develop innovative ideas to address the shortcomings, if any, contribute to the preparation of students and reduce the negative impact likely to be associated with the emergence of 4IR.

Beyond the introductory section of this article is a review on related literature covering the aspects of Work Integrated Learning and the Fourth Industrial Revolution. In addition, underpinning theories relevant to the research focus area are presented, as well as the methodological approach adopted. Discussions on the findings are followed by a conclusion and recommendations.

\section{Related Literature Review}

The global world is characterized by continuous changes in all aspects, social, economic, political, environmental, technological and otherwise. Similarly, the world of work is not left behind, with significant changes impacting employment, job tasks and skills level requirements. This is attested to by [23], on the swift global changes that are impacting the nature of knowledge, work and employment. With the increasing technological penetration into the world of work, dramatic changes are happening at exponential speed, thus creating uncertainty. Navigating through such shifts requires the need for innovative skills development to manage the potential impact. The role of education in such circumstances cannot be over-looked. According to Organisation for Economic Co-operation and Development [55], education is a tool that can equip learners with agency and a sense of purpose and the required competencies; it can shape and make the necessary contributions towards and beyond their lives. In view of this, [49] asserts the three pillars of education, namely, knowledge, competency, and values and skills needed for human advancement, to cope with the digital development of organizational productivity, and foster growth. Within the South African purview, education is one of the most important mechanisms for addressing the injustices of the past, prioritized in the National Development Plan's (NDP) Vision 2030, and takes a big chunk of government expenditure.

Against the backdrop, this article traced various strategies adopted in the South African Higher Education 
(HE) system towards skills development. The article specifically examined the concept of work integrated learning as a strategy for skills and knowledge acquisition.

\subsection{Deconstructing WIL: Rethinking Digitalized Knowledge Economy}

The wave of the Fourth Industrial Revolution has become the mantra of both formal and informal engagements across all spheres in the society. The concept of the Fourth Industrial Revolution as coined by Klaus Schwab indicates a period characterized by a range of new technologies that are fusing the physical, digital and biological worlds, impacting all disciplines, economies and industries, and challenging ideas about humanity [37]. The revolution combines technological and human capacities in an unprecedented way [48], through advancements such as Robotics, Artificial Intelligence (AI), Internet of Things (IoT), Augmented Reality (AR), Analytics, and Robotic Process Automation (RPA) [48]. According to [21], the revolution is a creation of new knowledge and values. The impact on the world of work still remains a research focus area. There have been predictions of both the negative and positive impact of 4IR on the world of work. While job losses have been predicted, new jobs are being anticipated to be created and the need for upskilling of the labour force to cope with the emerging jobs has become a matter of concern.

In view of this, the quality of graduates being pushed into the labour market often resonates in discourses. Concerns are that the value of a degree for employability is on the decline [56]. Given the dynamic changes in the business environment, industries demand skilled, innovative and adaptable graduates who can serve as agents of change in solving complex workplace problems. Studies have shown gaps between knowledge learnt in higher education institutions and skills required in the real world [54, 39, 69, 71]. In addition, [44] predicted increasing demand from higher education to improve the quality of graduates. Scholars have argued that classroom-based instructions [9] or a strong disciplinary knowledge base [2, 3], do not necessarily produce employability in graduates. This is disconcerting given the emerging disruptive technologies such as 4IR, which are changing all aspects of life, including the workplace and society in general. According to [50], these revolutionary changes will bring shifts in power, wealth and knowledge, and the need to be knowledgeable about the changes would ensure the enhancement of all benefits. This is emphasized in a recent \#4IRSA digital summit, where Professor Adam Habib stressed the need to train scholars to deal with the challenges of the $21^{\text {st }}$ century and develop the required technology to address the poverty, unemployment and inequality engulfing the nation [76]. In a similar context, the Employment and Labour Minister, Thulas Nxesi, stressed the need for upskilling and re-training of the workforce to cope with the challenges of 4IR [24]. With the increase in the acceleration and the rate of technological changes, it is therefore a fact that the workforce needs to be trained so as to grip the full benefit of the 4IR. In this manner, HEIs have been identified as one of the sources for skills development needed to steer the wheels of 4IR. Within the pedagogy are designed programs to enhance the integration of classroom and workplace learning, which varies across academic disciplines and countries. Such programs may include internship, industrial training, work placements, teaching practice, work integrated learning and in-service training. Accordingly, [46] argue that internship programs provide a complex practical experience required by students in dealing with the real-world workplace. From the South African perspective, most HEIs have adopted the concept of work integrated learning, and this is found in most Universities of Technology.

WIL has been identified within the pedagogy as a technique for closing the gap between industry requirements and HEI programmes. The South African Department of Higher Education and Training defines work integrated learning as "an umbrella term for any purposefully-designed learning programme that integrates theoretical knowledge with authentic practice in the workplace" [15]. Applied to a broader HEI environment, WIL encompasses a wide range of activities with a strong focus on industry partnerships [35]. WIL is applied across academic disciplines in higher education institutions. It comprises curricula and assessments, and integrates formal learning to workplace scenarios [10]. WIL is a collaborative framework designed for students to develop competence [15], improve employability [66], contribute actively to practice [25] and to the knowledge economy.

Research studies have shown a correlation between work integrated learning and the competence needed at workplace. [12] in their study noted that WIL approaches are closely integrated to university study, and professional and workplace practice. The replica effect is learning activities that allow for the application of disciplinary knowledge learned at the university to be practically applied to the real-world work context [12]. Further research studies indicate that, as an educational approach, WIL allows students to apply theory to practice [16], and enhances learning, development and employability $[52,45$, 74]. It is also documented that WIL enhances students' skills development; deepens and embeds knowledge and understanding, and enhances work-related capabilities [72, $65,74,41]$. In other words, WIL ensures development of competence critical to students' entry into the workforce $[58,16]$. [72] assert that a good practice in WIL would facilitate the integration and alignment of theory to practice. This would ensure skills and attribute development, effective workplace communication development and learning that incorporate cognition and practical wisdom [75]. Given this background, it is believed that an effective 
implementation of a WIL program would go a long way in preparing students to embrace the challenges of 4IR.

\subsection{Theoretical Perspectives on Work Integrated Learning and Skills Acquisition}

The concept of WIL is well documented in South African HEI systems $[15,10]$. The underpinning framework for this study is drawn from the historical theories of learning in which [14] defines learning "as the process whereby knowledge is created through the transformation of experience". Viewing learning from an educational lens and workplace setting entails two aspects: experiential education and experiential learning. [60] defines experiential education as the philosophical process that guides the development of structural and functional learning experiences. Similarly, the scholar notes that experiential learning addresses the specific techniques or mechanisms needed by an individual to meet learning goals and acquire knowledge ([60]. [20] states that most approaches to the epistemology of learning draw from earlier philosophies on experiential learning. In Kolb's [14] view, experiential learning addresses the learner's internal cognitive processes which comprise of four modes: concrete experience, reflective observation, abstract conceptualization and active experimentation. Each stage of the mode allows a learner to feel, watch, think and act across dimensions, and if well implemented, enhances optimal learning.

The stages of learning in developing an integrated framework for a WIL program comprise planning/designing, delivering, evaluation and market needs [63]. These cannot exist in a vacuum, hence the need for support structures. [31] notes that the pillars for effectiveness of such learning within the WIL context involve stakeholders which include the participating organization, curriculum and people. [77], denotes it as 3Ps (Participating organizations, People involved, and Programme structure) responsible for curriculum design, delivery and evaluation. According to [63], the initial stage of planning or designing addresses the relationship between HEI and the participating organization and the delivery and evaluation relates to the programme aligned to the market needs for the people involved [63]. The researchers here adopt an integrated conceptual framework comprising of [63] stages of learning and the [31] three pillars that support learning, as presented in Figure 1.

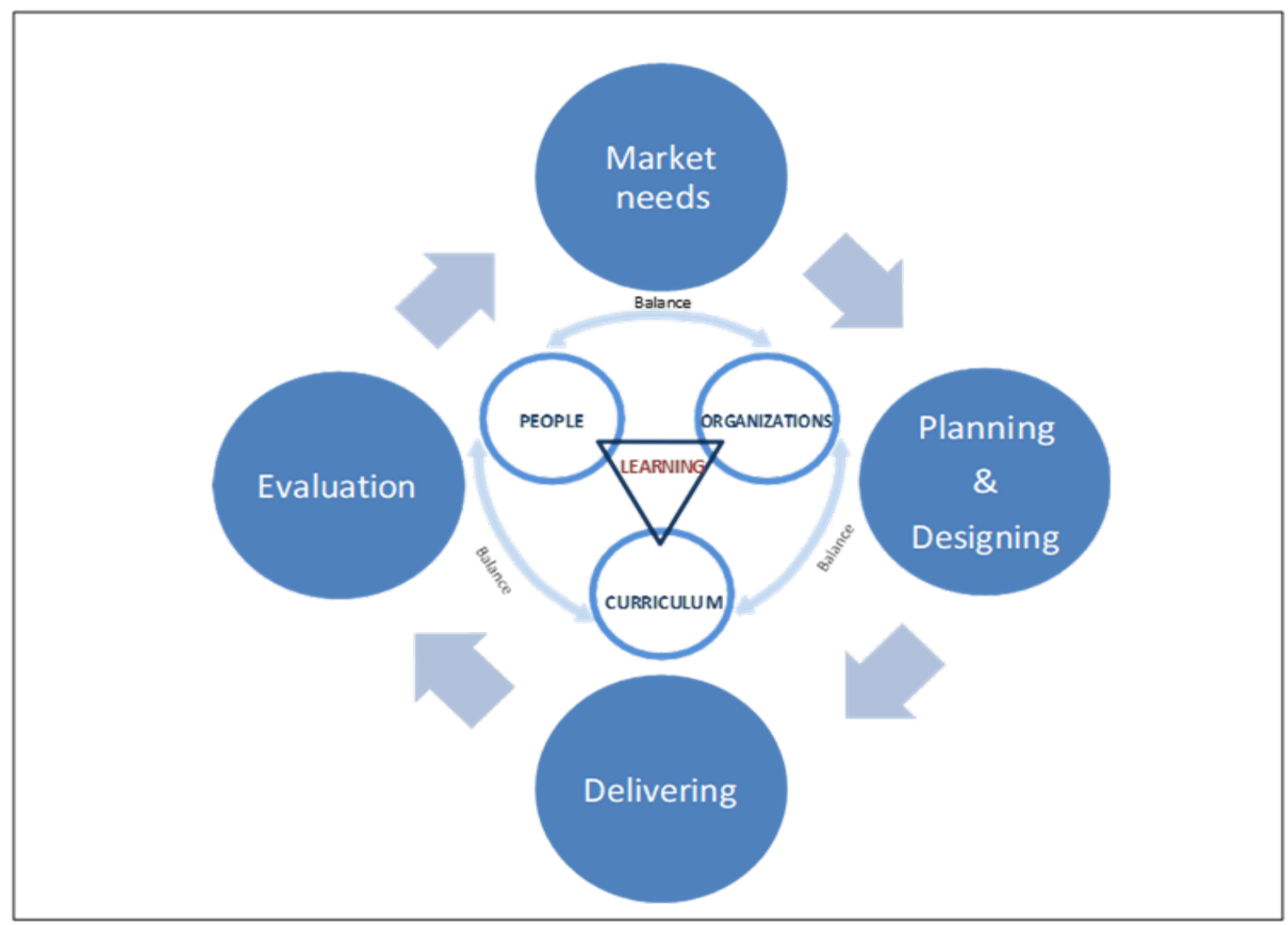

Source: [60]

Figure 1. A Conceptual Framework of a WIL program 
In view of Figure 1 and within the limits of this article, organizations are the HEI and the host companies and people include the students, HEI and the host companies. Developing curriculum takes into consideration the needs of the market, and incorporates input from all the stakeholders (the student and the organizations). [7] labelled it an integrated curriculum because it develops and delivers learning experiences aligned to the market needs. This clearly indicates the inter-relationship amongst the pillars or agents of a WIL programme. [43] labelled it a trio relationship of student, HEI and the industry or employer, which cannot operate autonomously. [1] note that each pillar plays definite responsibilities, performs specific functions, and achieves benefits as a result of the overall involvement. In such a relationship, [15] notes that the role of HEIs in implementing the WIL core programmes is enabled through government policies. In addition, HEIs provides opportunities for students to transform their learning experiences into practical knowledge [33], and builds relationships and continued engagement with industry [67]. On the other hand, the employers, or host organizations, provide opportunities for students to learn in the workplace while students use WIL as a learning opportunity [15].

Given this scenario, an effective WIL programme entails a good relationship and continuous engagement involving all stakeholders, which presumably provides valuable learning opportunities for appropriate skills acquisition, especially for the 4IR.

\section{Research Methodology}

This study adopts a constructivist research paradigm in order to understand the subjective and practical reality of the research problem. The research design used is principally action research, defined by [59] as an approach used in designing studies which seek to inform and influence practice. The researchers adopted action research design for numerous reasons. [27] note the historical locale of action research in the tenets of education. [28] has long asserted the on-going gap between academia and practice, and [26] prompted the need for more actionable knowledge.

Applied to an educational setting, action research involves participants conducting inquiry into their practices to ensure improvement in teaching and learning programs and to create impact on the local policy and practices [5]. In line with this assertion and in constructing the WIL framework as depicted in Figure 1, are three main stakeholders (the student, the HEI and the industry), considered the participants with shared common goal in what [22] viewed as a community of practice. Taking inspiration from the latter on the philosophy of community of practice, [59] argue that it allows for engagement and collaborative relationship and for development to flourish. Scholars note that action research encourages shared goals towards educational change [5] improves the research subjects' capacities in problem-solving, skills development, self-determination, functioning and decision-making processes [6] enables transformation of action to practice [68], and improves practice as part of the process of change. These insights support [27] assertion of a positive interplay involving action research, curriculum and learning. It is therefore worthwhile to note the triad relationship that exists within the WIL stakeholders identified in this study.

The researchers adopted a qualitative research approach using two sets of respondents. The first sample is a group of Faculty of Management students pursuing a National Diploma in a University of Technology in South Africa. Given the large numbers of students involved, the researchers utilized a cluster non-probability sampling technique and used a structured interview schedule to collect data from the Human Resource Management discipline totaling 56 students. The structured interview schedule was designed to gain a deeper understanding of students' opinions about the learning that took place during the WIL programme. Out of the 56 students enrolled in the discipline, only 40 got a placement for WIL via the university's collaborative relationship with industry at the time of data collection. Out of the 40 students sampled, only 26 interview schedules were appropriately answered and considered ideal for analysis.

The second sample used for data collection is a report of engagement involving the students, the UoT and the industry. The industry in this case is the public sector and specifically, the Department of Education. The engagement was conducted as a focus group discussion involving break-away discipline sessions and a general discussion by all the stakeholders. Before the close of the event, a draft report emerging from the entire engagement was presented to the stakeholders involved to ensure their input, and experiences shared were captured appropriately. A general consensus was achieved which ascertained the reliability and validity of the research instrument as well as the study.

Thematic data analysis was used and clustering and partitioning of codes informed categories/themes that emerged from the data. Verbatim responses were extracted and where necessary, the data was presented at both the semantic and latent levels. The analysis of the data was presented in line with each research objective. Secondary data was used to augment the data from the primary sources.

\subsection{Data Presentation}

\subsubsection{Research objective $1\left(\mathrm{RO}_{1}\right)$}

To provide insight into the use of WIL in preparing students to acquire the necessary skills and knowledge in readiness for the $4 \mathrm{IR}$

In eliciting information to address research objective 1 $\left(\mathrm{RO}_{1}\right)$, the researchers focused on data emanating from the 
structured interview schedule meant for only the WIL students. The researchers asked questions addressing the themes/categories around 'learning and skills acquisition'. The questions involved learning in classrooms and applications in performing tasks at the workplace. The data that emerged showed that $88 \%$ of the respondents performed jobs relevant to the field of Human Resource Management (HRM) practices, and were able to link learning from modules done in the classroom to tasks carried out in the workplace. $12 \%$ of the respondents claimed that tasks carried out during their WIL programs were irrelevant to the modules undertaken at the university. As noted by R17, No: it was not relevant. I was doing filing stuff.

The themes emerging from the data are 'learning', 'skill development', and 'task mismatch'.

\subsubsection{Research objective $2\left(\mathrm{RO}_{2}\right)$}

To understand the challenges facing stakeholders in the use of WIL to build an effective workforce

Data for addressing $\mathrm{RO}_{2}$ emerged from both the interview schedule and the focus group discussion. Questions were asked under the theme "challenges", to elicit information that would help in answering $\mathrm{RO}_{2}$, and responses were collated under similar patterns, themes/categories.

The data that emerged from the interview schedule indicated that $23 \%$ of the respondents started WIL later than scheduled due to difficulty in getting a placement, thus resulting in a shorter WIL duration. In addition, $46 \%$ of the respondents indicated lack of specific skills to carry out basic daily job requirements, translating to increased workload, as noted by R9:... I lack typing skills so I took longer time to finish the job.

Furthermore, $50 \%$ of the respondents indicated battling with skepticism, self-determination or self-efficacy, which impacted on their ability to adapt or adjust to the new work environment.

R3 noted: I was afraid to go to work, during the WIL, there was a lot of work that was to be done....

R4 noted: I couldn't adapt quickly to the work.

R12 noted challenges faced include adjusting to the work environment and also being on time on daily basis.

Another challenged indicated by R12 was...to not fear asking and also...the work environment by interacting with the colleagues even at lunch.

R25 noted: ...the time to adapt to the work environment seemed to be a problem facing the challenges of making mistakes.

R26 indicated: ...I faced challenge of motivation to go to work.

Diversity and relationship management emerged as concerns by the students.

R7 noted: ...working with old people, communication at first was a problem for me, I didn't know how to relate with them.

R20 also noted: ... I faced working with different personalities especially in school meetings, the parents....

Last but not least emerging from the data, is the inability to provide feedback on task completion.

R17 said: ...the department that I worked was not right, they were giving us stuff and not checking to use if I do well or not.

At the latent level, the researchers interpreted the message relayed by $\mathrm{R} 17$ as ...the department that I worked with was not efficient in providing feedback on tasks completed by the students.

The findings from the data emerged under the categories, 'skills insufficiency and feedback', 'time management', self-efficacy' and 'diversity management'.

Similarly, data from the focused group discussions were collated. Data emanated from the industry representatives shows concerns over the quality of students, early engagement, balancing module content, WIL duration.

From the UoT representatives, came concerns over task mismatch, and orientation of WIL students.

\subsubsection{Research objective $3\left(\mathrm{RO}_{3}\right)$}

To determine the role of the stakeholders in ensuring effective development of skills and knowledge.

Data emanating from $\mathrm{RO}_{2}$ led to a dialogue session between the UoT and the DoE representatives. The UoT representatives stressed on the need for the employers to orientate students which would help them in coping with the demands of the job. On the other hand, the DoE representatives asserted on the need for a longer internship period for the UoT students instead of the usual 10weeks which is deemed too short a time for an appropriate learning. The findings were presented under the theme, 'orientation and curriculum'.

The summary of the findings for the three tested research objectives is presented in Table 1.

Table 1. Summary of Research Findings

\begin{tabular}{|c|c|}
\hline $\begin{array}{c}\text { Study Research } \\
\text { Objectives }\end{array}$ & Summary of Findings \\
\hline Research Objective 1 & Learning, \\
$\left(\mathrm{RO}_{1}\right)$ & Skill development \\
& Task mismatch \\
\hline & Skills insufficiency and feedback \\
& Time management \\
& Self-efficacy \\
& Diversity management \\
Research objective 2 $\left(\mathrm{RO}_{2}\right)$ & Quality of students \\
& Early engagement \\
& Module content \\
& WIL duration \\
& Task mismatch \\
& Orientation \\
\hline Research objective $3\left(\mathrm{RO}_{3}\right)$ & Orientation and Curriculum \\
\hline
\end{tabular}

\section{Discussion of Research Findings}

The discussion of the research findings was aligned to the roles of stakeholders under the adopted triad framework. 
This is on the premise that a triadic approach to WIL in which the students, HEI and host organizations, work in close collaboration, maximizing experience [62]. In view of this, the themes that emerged from the analysis of the data are discussed under the roles of the student, the roles of the university and the roles of industry in developing the required skills and knowledge needed in the 4IR era.

The thematic analysis of the data highlighted time-management, self-efficacy and diversity management. The researchers believed that the student has the sole responsibility of addressing these concerns. This is because the respondents acknowledged doing a module that addressed time- management and participated in the practical aspects of the module prior to commencing WIL. Though, application of theories learnt in a classroom setting may be different in practice, the onus is on the student to develop personal coping strategies under the circumstances.

The HEI is responsible for the early engagement with the employer, determination of the WIL duration and quality improvement through teaching, learning and curriculum development. Because the labour market is saturated and vacancies for WIL become highly competitive, early engagement with the employers may likely increase the absorption rate of the students into the WIL program. A longer-term WIL duration may likely improve the learning and development of the students.

The employers or host organizations are responsible for the orientation and provision of feedback to the WIL students. The importance of orientation as a component of the WIL framework in increasing job performance and productivity of the organization has been acknowledged [3]. Similarly, the concept of feedback within the pedagogy has long been a powerful tool for evaluation and improving learning outcomes. Studies have shown the role of feedback in the learning and development of students [19, 8]. In a workplace environment, feedback impacts on both the student and the supervisor positively. While feedback improves the students' work efficiency, [17], noted its potential in enhancing resumé, and future job and promotions opportunities for the supervisor.

Though a minimal percentage of respondents indicated a mismatch between theory and practice, researchers felt the need not to disregard this issue given the sample size and on-going challenges facing the higher education system. [34], raised concerns over job mismatch which to a large extent has contributed to the quality and employability of graduates, thus increasing youth unemployment. This therefore calls for adherence to the good practice principles such as authenticity, alignment of activities with learning outcomes, adequate workplace support, access to supervisors and preparation [11].

The thematic analysis indicates that nearly all the students involved in the WIL program acquired learning and developed their skills. This is true for similar studies conducted on WIL and its impact on students across disciplines globally $[4,30,32,51,36,57]$. As noted earlier, the 4IR has been associated with technological disruptions, transformative changes to the business sector and all aspects of humanity. Transformations to the employment landscape and skills requirements are envisaged to be high. [77] notes that to manage the trends successfully, we require potential reskilling and upskilling of talent across academic backgrounds in all industries. In addition, an understanding of industry requirements of soft skills as opposed to hard skills, is needed. Narrowing the discussion to the boundaries of this article, developing these needed skills to sustain 4IR requires commitment from all the stakeholders. In other words, all the stakeholders should be committed to learning that enhances skills development. Having said this, the researchers believe that the themes emerging from the data on learning, skill insufficiency/development, and curriculum development, centred on the student, the university and the employer. In this case, a student is expected to be committed to his/her own learning. By so doing, the student takes responsibilities for determining what to learn, identifying the resource and how best to make optimum use of it; valuing and reporting on the learning [61]. The alignment of the module content/curriculum development remains the responsibility of the university in accordance with government policies. Employers bear the burden of informing the university of specific skills needed by students to cope with the job requirements at workplace. This is to enable the HEI to build such skills into the curriculum/module content. The non-alignment of curriculum to labour market requirements poses challenges such as skills/workplace mis-match, inability to match soft and hard skills, less quality/competent university graduates, etcetera $[30,32]$. Similarly, the alignment of the education system to the labour market demands would go a long way in addressing these challenges $[53,54]$

\section{Conclusions and Recommendations}

Education and skills development are strategic components of every country's long-term success. The on-going challenges in the South African higher education system are likely to intensify with the dynamic changes in the world of work. Predictions on South Africa achieving the full potential of 4IR lean on the ability of government to improve the quality of education and skills to meet economic needs. The essence of this study was to highlight the possibilities of WIL being an enabler for student work preparedness in the wave of 4IR. In ensuring a minimal negative impact and to maximise the full benefit potential of 4IR, it is of utmost importance to prioritize skills development. Effective skills development should be based on appropriate implementation of theories and practice. Given the foregoing, the article identified three pillars responsible for fostering advancement in the current and 
future skills demand of the labour market, namely, the student, the HEI and the employer. A critical outcome of this triad relationship is the need to benchmark the learning needs using curriculum and learning outcome against the labour market requirement. Based on the review of literature, the researchers adopted [63] WIL framework, that highlighted the importance and responsibilities of each stakeholder for effective skills and knowledge development. The adopted framework could serve as a reference point in the development of the 4IR skills needed specifically for Human Resource Management students.

Respondents indicated that the duration of the WIL program for the sampled discipline is relatively small. There were concerns that the WIL period almost ends at the point the respondents were beginning to adapt to the new work environment. Though the duration of the WIL program may have been aligned to the National Qualifications Framework descriptor for the level, it may be worthwhile for the UoTs with similar concerns to revisit the WIL duration to ensure the overall purpose of a WIL program is achieved. To ensure learning is maximized, the employers should also provide control measures that encourage feedback. Within the pedagogy, feedback has long been posited as a learning strategy to maximize on skills and knowledge creation.

\subsection{Limitations of the Research Study}

The study is limited to Human Resource Management students only and the sample studied is not large enough to generalize on the findings. A greater sample of potential host organisations may have improved on the validity and reliability of this study. Future research may cover other disciplines that make up the faculty to ascertain possible similarities and differences from the data.

\section{Acknowledgements and Funding}

The authors show appreciation to the Durban University of Technology (DUT), Research and Postgraduate Support Directorate, for the financial assistance rendered to ensure the completion of this project. The opinions, findings, conclusions or recommendations expressed in this study are those of the authors and do not by any means reflect the views of the funders.

\section{Authors' Contributions and Disclosure Statement}

The authors contributed equally to the development of this research piece. We therefore declare no conflict of interest and approve the article for publication.

\section{REFERENCES}

[1] A. Martin, \& H. Hughes. How to Make the Most of Work Integrated Learning: A Guide for Students, Lecturers \& Supervisors. New Zealand: Massey University Press. 2009.

[2] A. Martin, \& M. Rees. Work Integrated Learning: More Than Enhancing Employability and Graduate Attributes. 2018. Massey University, Wellington: Ako Aotearoa.

[3] B. Freudenberg, M. Brimble, \& C. Cameron. WIL and generic skill development: The development of business students' generic skills through work-integrated learning Asia-Pacific Journal of Cooperative Education 12, 2: 79-93, 2011.

[4] B. Khampirat, C. Pop, \& S. Bandaranaike. The effectiveness of work-integrated learning in developing student work skills: A case study of Thailand. International Journal of Work-Integrated Learning, 20, 2: 127-146, 2019.

[5] B. M. Hines, A. Henze, C. Ivanova, L. Rowland, L. Waggoner, \& M. Lisak. Action Research in Education. 2016. London: Oxford University Press. Available at: https://dx.doi.org/10.1093/obo/9780199756810-0140

[6] B. W. M., Boog, L. Keune \& C. Tromp. Action Research and Emancipation. Journal of Community \& Applied Social Psychology. 13: 419-425, 2003. Available at: 10.1002/casp. 747

[7] Cedefop. Learning outcomes approaches in VET curricula: a comparative analysis of nine European countries. 2010. Luxembourg. Publications Office. Available at: http://www.cedefop.europa.eu/EN/Files/5506_en.pdf

[8] C. Hughes. Assessment planning: A practical workshop with Alverno College. OLT AAGLO and University of Queensland, Brisbane, 30-31 May 2013. [unpublished notes from workshop].

[9] C. M. Govender, \& M. Wait. Work Integrated Learning Benefits for Student Career Prospects- Mixed Mode Analysis. South African Journal of Higher Education 31, 5:49-64, 2017. Available at: http://dx.doi.org/10.28535/31$5-609$

[10] Council on Higher Education (CHE). Work-Integrated Learning: Good Practical Guide. HE Monitor No 12. Pretoria, South Africa: Council on Higher Education. 2011. Available at: https://www.che.ac.za/sites/default/files/publi cations/Higher_Education_Monitor_12.pdf

[11] C. Smith. Evaluating the Quality of Work-Integrated Learning Curricula: A Comprehensive Framework. Higher Education Research \& Development 31, 2: 247-262, 2012.

[12] C. Smith, \& K. Worsfold. WIL curriculum design and student learning: A structural model of their effects on student satisfaction. Studies in Higher Education, 39, 6: 1070-1084, 2014. Available at: https://doi.org/10.1080/030 75079.2013.777407

[13] D. A. Caguimbal, D.C. Delacion, A.O. Medina, M. S. Mendoza, R.J.M. Mendoza, \& M.M. Sanchez. Level of Awareness of the Maritime Students on the Outcomes Based Education. Educational Research International, 2, 1:7-12, 2013. 
[14] D. A. Kolb. Experiential learning: experience as the source of learning and development. 1984. Upper Saddle River, NJ: Prentice Hall.

[15] Department: Higher Education and Training. Republic of South Africa. A Framework for providing Work-integrated learning in Technical and Vocational Education and Training Colleges. 2013.

[16] D. Jackson. Employability skill development in work-integrated learning: Barriers and best practice. Studies in Higher Education, 40, 2: 350-367, 2015. Available at: $10.1080 / 03075079.2013 .842221$

[17] [17] D. Jackson, D. Rowbottom, S. Ferns, \& D. McLaren. Employer understanding of Work-Integrated Learning and the challenges of engaging in work placement opportunities, Studies in Continuing Education, 39:1, 35-51, 2017. Available at: DOI:10.1080/0158037X.2016.1228624

[18] D. Jackson, \& N. Wilton. Developing career management competencies among undergraduates and the role of work-integrated learning. Teaching in Higher Education, 21(3), 266-286, 2016. Available at: https://doi.org/10.1080/13562517.2015.1136281

[19] D. Peach, E. Ruinard, \& F. Webb. Feedback on student performance in the workplace: The role of workplace supervisors. Asia-Pacific Journal of Cooperative Education. 15, 3: 241-252, 2014.

[20] D. T. Moore. Forms and issues in experiential learning. New Directions for Teaching and Learning, (124), 3-13, 2010. 10.1002/tl.415 Wiley Periodicals, Inc.

[21] D. Yoon. What We Need to Prepare for the Fourth Industrial Revolution. Healthcare informatics research 23, 2: 75-76, 2017. Available at: doi:10.4258/hir.2017.23.2.75 (Accessed on 02 September 2019.)

[22] E. Wenger. Communities of Practice: Learning, Meaning, and Identity. 1998. Cambridge, UK: Cambridge University Press.

[23] F. A. Muhammet, \& E. Esma. The psychometric properties of the Turkish version of the learning potential of the workplace scale. Paper presented at the 2018 European Conference on Educational Research (ECER), Free University of Bozen-Bolzano, Italy.

[24] Fin24. 4IR will see 'some jobs go', says labour minister. Aug 282019 13:48. Available at: https://www.fin24.com/Econo my/4ir-will-see-some-jobs-go-says-labour-minister-201908 28

[25] F. Trede. Role of work-integrated learning in developing professionalism and professional identity. Asia-Pacific Journal of Cooperative Education 2012, 13, 3: 159-167, 2012.

[26] G. A. de Zeeuw. Helping others: Project or research? Journal of Community \& Applied Social Psychology 13, 496-503, 2003.

[27] G. Casey, \& T. Evans. Action research to support the integration of social media in the classroom. Action Research, 16, 2: 127-151, 2018. Available at: https://doi.org/10.1177/1476750316674539

[28] G. L. A. Romme. Action Research, Emancipation and Design Thinking. Journal of Community \& Applied Social
Psychology 14: 495-499, 2004.

[29] G. J. Maarman, \& K. Lamont-Mbawuli. A review of challenges in South African education and possible ways to improve educational outcome as suggested by decades of research, Africa Education Review, 14:3-4, 263-289, 2017. Available at: DOI:10.1080/18146627.2017.1321962

[30] H. T. T. Diem, K. Kanyaprasith, N. Phonphok, C. Pruekpramool, \& N.K.T. Son. Enhancing Pedagogical Profession and Personal Improvement for Vietnamese Student Teachers through Reality-experienced Internship Program in Thailand. Universal Journal of Educational Research 8, 1: 112-118, 2020. Available at: DOI: 10.13189/ujer.2020.080113

[31] J. Garnett. University Work Based Learning and the Knowledge Driven Project in Rounce, K. and Workman, B. (Eds.): Work Based Learning in Healthcare. 2005. Chichester: Kingsham.

[32] J.M. Laguador, N. H. Chavez-Prinsipe, \& E.L. De Castro. Employability Skill Development Needs of Engineering Students and Employers' Feedback on Their Internship Performance. Universal Journal of Educational Research 8, 7: 3097-3108, 2020. Available at: DOI: 10.13189/ujer.2020.080738

[33] J. Orrell. The Conversation. Work Integrated Learning: why is it increasing and who benefits? April 29, 2018 10.12pm SAST. Available at:https://theconversation.com/work-integ rated-learning-why-is-it-increasing-and-who-benefits-9364

[34] J. W. Roberts. Beyond learning by doing: theoretical currents in experiential education. 2012. New York: Routledge.

[35] K. Macdonald, C. Cameron, M. Brimble, B. Freudenberg, \& D. English. Realizing the professional within: The effect of work integrated learning. Asia-Pacific Journal of Cooperative Education, 15, 2:159-178, 2014.

[36] K. Ngwane. Perceptions on the Effectiveness of Work-Integrated Learning: A Case Study of a Selected Higher Education Institution in South Africa. Unpublished dissertation. Durban University of Technology. 2015. Available at: http://hdl.handle.net/10321/2522

[37] K. Schwab. The Fourth Industrial Revolution. 2016. New York: Crown publishing group.

[38] K. Tan, C. M Chan, P. Subramaniam, \& W. L. Ping. The effectiveness of outcome based education on the competencies of nursing students: A systematic review. Nurse Education Today 64: 180-189, 2018.

[39] L. Büth, V. Bhakar, N. Sihag, G, Posselt, S. Böhme, K. S. Sangwan, \& C. Herrmann. Bridging the qualification gap between academia and industry in India. Procedia Manufacturing 9, 275 - 282, 2017.

[40] L. Chisholm. Reviews: The challenge of South African schooling: dimensions, targets and initiatives. In Transformation Audit: From Inequality to Inclusive Growth, 2011.

[41] L. Cooper, J. Orrell, \& M. Bowden. Work integrated learning: a guide to effective practice. 2010. New York: Routledge. 
[42] L. Maddock, \& W. Maroun. Exploring the Present State of South African Education: Challenges and Recommendations. South African Journal of Higher Education 32, 2: 192-214, 2018. Available at: http://dx.doi.org/10.20853/32-2-1641

[43] L. McEwen, K. M. O'Connor, C. Williams, \& H. Higson. Engaging employers as partners in work-based learning assessment: proposal for a quality enhancement framework. Learning and Teaching in Higher Education, 4, 2: 62-89, 2010 .

[44] McKinsey Global. Jobs lost, jobs gained: Workforce transitions in a time of automation. McKinsey Global Institute. 2017. Available at: https://www.mckinsey.com/ / media/mckinsey/featured $\% 20$ insights/future $\% 20$ of $\% 20$ orga nizations/what $\% 20$ the $\% 20$ future $\% 20$ of $\% 20$ work $\% 20$ will $\%$ 20 mean $\% 20$ for $\% 20$ jobs\%20skills\%20and\%20wages/mgi-j obs-lost-jobs-gained-report-december-6-2017.ashx

[45] M. Kennedy, S. Billett, S. Gherardi, \& L. Grealish. Practice-based learning in higher education: jostling cultures. In M. Kennedy, S. Billett, S. Gheardi \& L. Grealish (Eds), Practice-based learning in higher education: Jostling cultures (pp. 1-14), 2015. New York, NY: Springer.

[46] M. L. Negrut, A. Mihartescu, \& M. L. Mocan. Aspects of the Internships Importance in Human Resource Training. Procedia - Social and Behavioral Sciences 191:308 - 314, 2015

[47] M. Metcalfe, M. Orkin and G. Jenny. Our pass rate focus is too narrow. Sunday Times: 15 Jan, 2012: 6.

[48] M. Schäfer. The fourth industrial revolution: How the EU can lead it. European View, 17(1), 5-12, 2018. Available at: https://doi.org/10.1177/1781685818762890

[49] M. Vitiello. The Challenges for Future Education: A Global Perspective. Eruditio: e-Journal of the World Academy of Arts \& Science 2, 4: 56-59, 2018.

[50] M. Xu, J. M. David, \& S. H. Kim. The Fourth Industrial Revolution: Opportunities and Challenges. International Journal of Financial Research 9, 2: 90-95, 2018.

[51] N. F. Dwesini. The role of Work-Integrated Learning (WIL) in enhancing employability skills: graduate perspectives. African Journal of Hospitality, Tourism and Leisure 6, 2: 1-9, 2017.

[52] N. McRae, \& N. Johnston. The development of a proposed global work-integrated learning framework. Asia-Pacific Journal of Cooperative Education 17, 4: 337-348, 2016. Available at: https://www.ijwil.org/files/APJCE_17_4_337 _348.pdf (Accessed on 13 September 2019.)

[53] O. D. T. Kim. Organizing Experiential Learning Activities for Development of Core Competences of Technical Students in Vietnam. Universal Journal of Educational Research 7(1): 230-238, 2019. Available at: DOI: 10.13189/ujer.2019.070129

[54] O. E. Okeke-Uzodike, \& M. Naude. The Perceived Work-Readiness of Supply Chain University Graduates at a Large FMCG Company. Journal of Contemporary Management 15, 424-446, 2018.

[55] Organisation for Economic Co-operation and Development (OECD). The future of education and skills: Education 2030. Directorate for Education and Skills-OECD. Paris Cedex
16-France, 2018. Available at: https://www.oecd.org/educat ion/2030/E2030\%20Position\%20Paper\%20(05.04.2018).pd $\mathrm{f}$

[56] P. Jassal, \& H. Clark. The new learning economy and the rise of the working learner: An anthology of recent evidence. 2016. Available at: https://pages2.act.org/riseofworkinglear ners.html

[57] P. Jonck. The mitigating effect of work-integrated learning on graduate employment in South Africa. Africa Education Review. 11, 3: 277-291, 2014.

[58] P. Rambe, 2018. Using Work Integrated Learning programmes as a strategy to broaden academic and workplace competencies. SA Journal of Human Resource Management, 16, (0), a999, 2018. Available at: $<$ https://sajhrm.co.za/index.php/sajhrm/article/view/999/14 $58>$.

[59] P. Reason, \& H. Bradbury. The SAGE Handbook of Action Research: Participative Inquiry and Practice (2nd edition). 2008. London: SAGE.

[60] P. Robert. Job mismatch in early career of graduates under post-communism. International Journal of Manpower, 35, 4: 500-513, 2014. Available at: https://doi.org/10.1108/IJM-0 5-2013-0113

[61] R. C. W. Webber-Youngman. Life skills needed for the 4th industrial revolution. The Journal of Southern African Institute of Mining and Metallurgy 117, 4, 2017.

[62] R. Dalrymple, C. Kemp, \& P. Smith. Characterising Work-Based Learning as a Triadic Learning Endeavour. Journal of Further and Higher Education 38, 1: 75-89, 2014.

[63] R. Ferrandez, T. Kekale, \& D. Devins. A framework for work-based learning: Basic pillars and the interactions between them. Higher Education, Skills and Work-Based Learning. 6, 1:35-54, 2016.

[64] R. Singh. Current trends and challenges in South African higher education: Part 1. South African Journal of Higher Education 29, 3: 1-7, 2015.

[65] S. Ferns, L. Russell, \& C. Smith. "Designing Work Integrated Learning to Optimise Student Employment Readiness". In Research and Development in Higher Education: Learning for Life and Work in a Complex World, edited by T. Thomas, E. Levin, P. Dawson, K. Fraser, and R. Hadgraft, 161-75, 2015. Melbourne: HERDSA.

[66] S. Ferns, V. Dawson, \& C. Howitt. Framework for enhancing graduate employability. International Journal of Work-Integrated Learning 20, 2: 99-111, 2019.

[67] S. Grand-Clement. Digital learning education and skills in the digital age. An overview of the consultation on digital learning held as part of the Corsham Institute Thought Leadership Programme. 2017. Santa Monica, California: RAND Corporation and Corsham Institute.

[68] S. Kemmis, What is to be done? The place of action research. Educational Action Research 18, 4: 417-427, 2010.

[69] S. Nagarajan, \& J. Edwards. The Role of Universities, Employers, Graduates and Professional Associations in the Development of Professional Skills of New Graduates. Journal of Perspectives in Applied Academic Practice 3, 2: 
26-37, 2015.

[70] Statistics South Africa. Quarterly Labour Force Survey (QLFS). Quarter 1: 2019. Statistical Release P0211. Pretoria South Africa. Available at: www.statssa.gov.za

[71] S. Taylor, \& C. M. Govender. Increasing employability by implementing a Work-Integrated Learning partnership model in South Africa - A student perspective. Africa Education Review 14, 1: 105-119. 2017. Available at: DOI: $10.1080 / 18146627.2016 .1224585$

[72] S. Schonell, \& R. Macklin. Work integrated learning initiatives: live case studies as a mainstream WIL assessment. Studies in Higher Education 44, 7: 1197-1208, 2019. Available at: DOI: 10.1080/03075079.2018.1425986

[73] The Presidency, Republic of South Africa. Address by President Cyril Ramaphosa to the 1st South African Digital Economy Summit, Gallagher Convention Centre, Johannesburg held on Friday 5 July 2019. Available at: http://www.thepresidency.gov.za/speeches/address-presiden t-cyril-ramaphosa-1st-south-african-digital-economy-summ it $\% 2 \mathrm{C}$-gallagher
[74] T. Wilson. A review of business-university collaboration. London, UK: Department of Business, Innovation and Skills. 2012. Available at: https:/www.gov.uk/government/upload s/system/uploads/attachment_data/file/32383/12-610-wilso n-review-business-university-collaboration.pdf

[75] V. Puncreobutr, Malee, \& Somjate. Linking work integrated learning and competency of graduates pursuing graduate diploma in teaching profession. Journal of Education and Practice, 7, 10: 121-127, 2016.

[76] Wits University. Embrace 4IR to address poverty, inequality and unemployment - Ramaphosa. 5 July 2019. Available at: https://www.wits.ac.za/news/latest-news/research-news/201 9/2019-07/embrace-4ir-to-address-poverty-inequality-and-u nemployment---ramaphosa.html

[77] World Economic Forum (WEF). Leading through the Fourth Industrial Revolution: Putting People at the Centre. White Paper. WEF in collaboration with Accenture. World Economic Forum, 91-93, 2019. Route de la Capite, CH-1223 Cologny/Geneva, Switzerland. www.weforum.org. 